\title{
Post-prostatectomy erectile dysfunction: contemporary approaches from a US perspective
}

This article was published in the following Dove Press journal:

Research and Reports in Urology

14 May 2014

Number of times this article has been viewed

\section{Zachary Hamilton' \\ Moben Mirza ${ }^{2}$ \\ 'Department of Urology, ${ }^{2}$ Division of Urologic Oncology, Department of Urology, University of Kansas, Kansas City, KS, USA}

\begin{abstract}
Success of cancer surgery often leads to life-changing side effects, and surgical treatment for malignant urologic disease often results in erectile dysfunction (ED). Patients that undergo surgical prostatectomy or cystoprostatectomy will often experience impairment of erections due to disruption of blood and nerve supply. Surgical technique, nerve sparing status, patient age, comorbid conditions, and pretreatment potency status all have an effect on postsurgical ED. Regardless of surgical technique, prostatectomy results in disruption of normal anatomy and nerve supply to the penis, which governs the functional aspects of erection. A variety of different treatment options are available for men who develop ED after prostatectomy, including vacuum erection device, oral phosphodiesterase 5 inhibitors (PDE5I), intracorporal injections, and penile prosthesis. The vacuum erection device creates an artificial erection by forming a vacuum via suction of air to draw blood into the penis. The majority of men using the vacuum erection device daily after prostatectomy, regardless of nerve-sparing status, have erections sufficient for intercourse. Phosphodiesterase 5 inhibitors remain a common treatment option for post-surgical ED and are the mainstay of therapy. They work through cyclic adenosine monophosphate and cyclic guanine monophosphate pathways and are recommended in all forms of ED. Intracorporal injections or intraurethral use of vasoactive substances may be a good second-line therapy in men who do not experience improvement with oral medications. Surgical placement of a penile prosthesis is typically the treatment strategy of choice after other options have failed. Semi-rigid and inflatable devices are available with high satisfaction rates. With careful patient counseling and proper treatment selection, patient satisfaction and improved erectile function can be achieved. We advise that patients use a vacuum erection device daily in the early postoperative period in combination with an oral PDE5I. For patients who do not respond to a vacuum erection device or PDE5I, consideration should be given to intraurethral alprostadil, intracorporal injections, or a penile prosthesis.
\end{abstract}

Keywords: vacuum erection device, phosphodiesterase inhibitor, intracorporal injection, penile prosthesis

\section{Introduction}

Cancer is a very significant health problem in the USA. Despite the fact that cancer remains the second most common cause of death, many patients will achieve cure or prolonged remission phases. The success of cancer treatment often leads to lifechanging side effects. The focus of this review will be the erectile dysfunction that develops as a result of surgical treatment for malignant urologic disease.

Prostate cancer is a prevalent disease and the second leading cause of cancer death in American men. Approximately 238,590 men were diagnosed with prostate cancer in 2013. ${ }^{1}$ The majority of men diagnosed are candidates for localized treatments, such
Correspondence: Moben Mirza

Division of Urologic Oncology,

Department of Urology, University

of Kansas Medical Center 390I

Rainbow Blvd MS 3016, Kansas City,

KS 66160, USA

Tel + I 9139456432

$\mathrm{Fax}+19135886668$

Email mmirza@kumc.edu 
as radical prostatectomy, radiation therapy, or brachytherapy. Furthermore, the development and utilization of prostate-specific antigen testing has led to increased detection of prostate cancer and consequent treatment. Similarly, urothelial cell carcinoma is the fourth most common cause of cancer death in American men. Radical cystectomy, a cornerstone in the treatment of muscle invasive bladder cancer, includes removal of the prostate gland. European Association of Urology guidelines recommend bilateral or unilateral nerve-sparing radical prostatectomy for patients with normal preoperative erectile function and organ-confined disease. For patients with high-risk disease, non-nerve-sparing surgery is the recommended approach. ${ }^{2}$ Regardless of approach, surgical removal of the prostate gland significantly affects erectile function. It has been shown that this side effect of surgical treatment affects quality of life for the majority of men. ${ }^{3}$

\section{Prevalence and importance of disease}

Erectile dysfunction may be the most common side effect of surgical treatment for prostate cancer, with a reported incidence as high as $90 \%{ }^{4,5}$ Unfortunately, it is difficult to adequately report this side effect after treatment because there are multiple possible instruments for the assessment of preoperative erectile dysfunction. Preoperative erectile function affects the postoperative subjective assessment of erectile function. Briganti et $\mathrm{al}^{6}$ reported that several preoperative factors such as patient age, preoperative erectile function, and overall health status significantly affected erectile function 2 years after treatment, regardless of treatment modality. Furthermore, there are multiple approaches for surgical treatment of prostate cancer (eg, nerve versus non-nerve sparing, open versus laparoscopic versus robotic, and with versus without lymph node dissection) and significant surgeon variability. ${ }^{7}$

Some men may believe that radiation therapy provides decreased rates of post-treatment erectile dysfunction compared with surgery. However, studies have shown that

Table I Treatments for erectile dysfunction

\begin{tabular}{l} 
Oral medications (phosphodiesterase type 5 inhibitors) \\
Sildenafil \\
Vardenafil \\
Tadalafil \\
Intracavernosal injections \\
Alprostadil \\
Phentolamine \\
Papaverine \\
Vacuum erection devices \\
Penile prostheses \\
Semi-rigid \\
Inflatable \\
\hline
\end{tabular}

cavernosal fibrosis and erectile dysfunction are similar between radiation and radical prostatectomy. ${ }^{8}$ Erectile dysfunction after radiation therapy occurs in $20 \%-80 \%$ of patients. ${ }^{9}$ Occlusive vascular disease, arteriogenic dysfunction, and venous leakage have been noted after radiation therapy, indicating that erectile hemodynamics are the etiology of post-radiation therapy erectile dysfunction..$^{9}$ One predictive factor of erectile dysfunction after radiation therapy is the radiation modality. In a comparison of conventional radiation therapy, three-dimensional conformal radiotherapy, and intensity modulated radiotherapy, the intensity modulated radiotherapy group showed the best results preserving erectile function. ${ }^{10}$

Poor sexual function, including erectile dysfunction, is associated with distress and compromised quality of life. ${ }^{11}$ The rate of prostatectomy-related regret increases over time, with up to $47 \%$ of men reporting regret 5 years after surgery. ${ }^{12}$ Post-surgical physical functioning, including poor sexual function, is associated with greater treatment regret as well. ${ }^{13}$ Interestingly, studies have suggested that irrespective of post-surgical urinary or sexual functioning, reducing the regret towards treatment may improve mental health. ${ }^{14}$ It is important to note that there are multiple treatment options for post-surgical sexual dysfunction, and post-surgical regret has a significant impact on overall quality of life. There are a variety of different treatment options available for men who develop erectile dysfunction after surgical treatment for prostate or bladder cancer involving prostatectomy (Table 1). The treatment of erectile dysfunction in this group is primarily based on studies in patients undergoing radical prostatectomy for prostate cancer. However, there is substantial crossover in treatment strategies for erectile dysfunction regardless of primary malignancy.

\section{Assessment of erectile function}

Many questionnaires exist to assess for erectile dysfunction. The International Index of Erectile Function is a commonly used and validated questionnaire for the evaluation of male sexual function. It assesses five domains of sexual function, ie, erectile function, orgasmic function, sexual desire, intercourse satisfaction, and overall satisfaction. ${ }^{15}$ The Sexual Health Inventory of Men is a simple five-question instrument that examines erectile function over the previous 6 months. It was created as a simpler and abridged version of the International Index of Erectile Function. ${ }^{16}$ The Erection Hardness Score is a singleitem, patient-reported outcome for scoring erection hardness, which is a simple and reliable tool as well. ${ }^{17}$ Lastly, the Quality of Erection Questionnaire is a six-item measure that measures satisfaction of men and the quality of their erections. ${ }^{18}$ These 
four examples are just a few of the options providers have for office-based assessment of erectile function.

\section{Mechanism of erectile function and dysfunction}

The penis contains three distinct cylindrical-shaped structures. The paired corpora cavernosa lie in the dorsal aspect, and the corpus spongiosum, which encases the urethra, lies on the ventral aspect. In the flaccid state, the cavernosal smooth muscles are contracted and allow a light amount of arterial blood flow for normal tissue health. During sexual arousal, neurotransmitters are released from the cavernosal nerve terminals, leading to dilation of the arterial blood vessels. This causes trapping of blood by the expanding sinusoids, compression of venous blood vessels, and reduction of venous flow. The penis then enters the erect state. ${ }^{19}$

Multiple mechanisms for smooth muscle relaxation exist. One main mechanism involves cyclic adenosine monophosphate and cyclic guanine monophosphate. Prostaglandins and other factors are involved with cyclic adenosine monophosphate signaling. Intracavernosal injection of prostaglandins can be utilized as an effective treatment for erectile dysfunction. Furthermore, it has been determined that hydrolysis, and thus termination, of cyclic adenosine monophosphate and cyclic guanine monophosphate is carried out by phosphodiesterases (PDEs). There are eleven families of PDE, but PDE5 is by far the principal PDE for termination of cavernous cyclic guanine monophosphate signaling. Medications aimed at inhibiting PDE5 are used to treat erectile dysfunction. ${ }^{19}$

Regardless of surgical technique, prostatectomy results in disruption of the normal anatomy and nerve supply to the penis. These nerves govern the functional aspects of erection. In 1982, Walsh and Donker ${ }^{20}$ described the innervation of the corpora cavernosa. The neurovascular bundle branches out from the pelvic plexus and courses posterolaterally outside the prostatic fascia and is covered by the levator fascia. The seminal vesicles are removed with the prostate gland; thus, the pelvic plexus, in close proximity to the tip of the seminal vesicles and anterior to the rectum, may be damaged. Prior to the introduction of nerve-sparing techniques, impotence was essentially guaranteed after radical prostatectomy. Walsh's studies utilizing nerve-sparing techniques improved potency rates to as high as $86 \%$ if both neurovascular bundles were spared. ${ }^{21}$ Besides a nerve-sparing approach, other preoperative risk factors or predictive factors have been evaluated. Multiple studies have shown that younger age, localized disease, good preoperative sexual function, as well as preservation of neurovascular bundles are predictive of higher postoperative potency. ${ }^{22,23}$
A period of erectile dysfunction is expected immediately postoperatively due to this neuropathic change. This leads to a loss of daily or nocturnal erections. A lack of cavernous oxygenation leads to secondary nonreversible damage of the corporal smooth muscle erectile tissue. ${ }^{24}$ Apoptosis and fibrosis develop within the corpora, resulting in further destruction of erectile tissue and collagen accumulation. ${ }^{25}$

\section{Erectile rehabilitation}

The practice of erectile rehabilitation is commonly performed in the clinical setting and previous reports have found that up to $87 \%$ of physicians utilize some form of erectile rehabilitation. ${ }^{26}$ Unfortunately, guidelines for this form of therapy are lacking, and this has led to wide variation in practice patterns, including PDE5 inhibitors, intracavernosal injections, vacuum devices, and intraurethral medications. The landmark clinical study in support of penile rehabilitation was reported by Montorsi et al, who developed the idea of penile rehabilitation and the positive effect of intracorporeal alprostadil injection after radical prostatectomy. ${ }^{27}$ Penile rehabilitation implies medical treatment at the time of or after surgery to improve the restoration of erectile function. The approach is intended to provide a reversal of penile hypoxia, penile atrophy, veno-occlusive dysfunction, and smooth muscle apoptosis, which are implicated in the pathophysiology of erectile dysfunction. Additionally, penile rehabilitation provides a long-term strategy rather than an on-demand strategy for an important quality of life outcome. Because the natural recovery of post-treatment erectile function may be as long as 2 years, ${ }^{28}$ it is possible that penile rehabilitation may simply accelerate the natural healing time of erections rather than saving patients from permanent erectile dysfunction.

Phosphodiesterase inhibitors have become the mainstay of penile rehabilitation after surgical removal of the prostate. ${ }^{4}$ Briganti et al reported that patients who underwent penile rehabilitation with PDE5 inhibitors after radical prostatectomy had significant improvement in erectile function recovery 3 years out from surgery. ${ }^{6}$ There were two large studies regarding penile rehabilitation that had conflicting results. One study compared sildenafil 50-100 mg daily with a placebo and reported significant improvement in the sildenafil group. However, the other study compared daily vardenafil versus on-demand medical therapy and determined that there was no significant difference between the two groups. All in all, there is no consensus on the appropriate PDE5 inhibitor formulation, dose, or timing after surgery.

\section{Vacuum erection device}

Early reports of the vacuum erection device concept date to 1874 when American physician John King noted that 
application of a "glass exhauster" to the male penis would increase its size. Geddings D Osbon, Sr, is regarded as the individual who popularized the vacuum erection device in the 1960s, and the US Food and Drug Administration approved the first marketed vacuum erection device in $1982 .{ }^{30}$ The vacuum erection device creates an artificial erection by forming a vacuum via suction of air to draw blood into the penis. A constricting band can then be placed at the base of the penis in order to maintain the erection. Colombo et $\mathrm{al}^{31}$ found that patients who practiced early application of a vacuum erection device without the constrictive band to produce "stretching" of the smooth muscle fibers showed significant improvement in spontaneous erectile ability as well.

In the $1980 \mathrm{~s}$, initial studies demonstrated the effectiveness and safety profile of the vacuum erection device. Nadig et al performed a study of 35 men with a $91 \%$ rate of erection rigid enough for vaginal penetration, and the rate of penile ecchymoses or petechiae was less than $25 \%{ }^{32}$ A vacuum erection device can be utilized regardless of the cause of erectile dysfunction and is considered a safe, effective first-line treatment option with no systemic side effects. It also provides a level of long-term cost saving as it is a one-time, flat fee for purchase. It can be used alone or in conjunction with other medical treatments. It does however require manual dexterity from the patient to control the device. Some men may complain of pain from the constriction band. Zippe et $\mathrm{al}^{33}$ reported a study in which patients successfully used the vacuum erection device after radical prostatectomy and confirmed its safety and tolerability, thus confirming it as a viable option for post-surgical erectile dysfunction.

In a prospective randomized trial, $80 \%$ of men using the vacuum erection device daily after a nerve-sparing radical prostatectomy had erections sufficient for intercourse. Further analysis showed that $32 \%$ had return of nocturnal erections and $17 \%$ had spontaneous erections. Of those patients who were unsatisfied with the device, the addition of sildenafil to device usage led to significant improvement in satisfaction in $77 \%$ of patients. ${ }^{29}$ Additionally, regardless of nerve-sparing status, early use of a vacuum erection device following radical prostatectomy facilitates early sexual intercourse and early patient and spousal sexual satisfaction. ${ }^{29}$ This was noted by Raina et al in a study of 109 radical prostatectomy patients who were randomized to a vacuum erection device daily for 9 months or observation alone. ${ }^{29}$ Eighty percent of patients using the vacuum erection device had vaginal intercourse twice per week, with a spousal satisfaction rate of $55 \%$. On a similar note, the vacuum erection device retains high efficacy rates despite a non-nerve sparing operation, with rates as high as $52 \% .{ }^{34}$ Another prospective randomized trial showed that daily use of a vacuum erection device in combination with a constriction band can preserve penile length at 6-month follow-up from treatment. ${ }^{35}$ Overall, the vacuum erection device has shown positive responses for penile rehabilitation, erectile function, and preservation of penile length. It should be considered a first-line option for post-surgical erectile dysfunction. ${ }^{30}$

\section{Phosphodiesterase type 5 inhibitors}

PDE5 inhibitors have been available for more than ten years and have become a mainstay of treatment of erectile dysfunction. The mechanism of action of PDE5 inhibitors includes blocking the breakdown of cyclic guanosine monophosphate, which is involved in the nitric oxide-dependent pathway of erections. ${ }^{19}$ An intact neurological mechanism must be present for patients to derive benefit from this class of medications. The three PDE5 inhibitors available are sildenafil, vardenafil, and tadalafil. These medications have minor differences in their half-lives, but all have been shown to improve erectile function.

PDE5 inhibitors remain a common treatment option for post-surgical erectile dysfunction and are the mainstay of therapy. They are commonly utilized in the on-demand setting and are also common in the penile rehabilitation setting with daily use protocols. Utilizing sildenafil every other day after radical prostatectomy can lead to preservation of cavernous body smooth muscle content. Furthermore, patients receiving a higher dose have an increase in smooth muscle content. ${ }^{36}$ PDE5 inhibitors can improve erectile function after surgical removal of the prostate from a basic science mechanism.

Typically, response rates to PDE5 inhibitors improve as time passes after radical prostatectomy and rates of response range widely from $15 \%$ to $80 \% \cdot{ }^{37,38}$ Nehra et $\mathrm{al}^{39}$ performed a prospective randomized study showing that patients undergoing treatment with vardenafil postoperatively had superior scores for intercourse satisfaction, orgasmic function, erection hardness, and overall sexual satisfaction compared with placebo. PDE5 inhibitors have been used with success in the penile rehabilitation setting as well, as discussed by Montorsi et al, and are now the standard initial treatment option in the community setting. ${ }^{38}$ Early use of a PDE5 inhibitor may lead to spontaneous return of erections as well. In a study assessing daily PDE5 inhibitor use for 9 months following prostatectomy, there was a seven-fold improvement in spontaneous erections at one year. ${ }^{34}$ These patients had normal preoperative erectile function and began use of medication 
(placebo, sildenafil $50 \mathrm{mg}$, sildenafil $100 \mathrm{mg}$ ) 1 month after prostatectomy. After the 9-month treatment period, patients went untreated for 2 months and the authors found that $4 \%$ of the placebo group and $26 \%$ of the sildenafil group had spontaneous return of erections sufficient for intercourse.

One of the most successful studies regarding PDE5 inhibitors in the post-surgical setting was a 2008 European, multisite, placebo-controlled trial by Montorsi et al. ${ }^{40}$ This trial enrolled over 600 patients 9 months post-prostatectomy who were randomly assigned to daily vardenafil penile rehabilitation, on-demand vardenafil, or placebo control. After the 9-month treatment period, there was a 2-month placebo washout period during which no patient received a PDE5 inhibitor for 2 months. After washout, a 2-month vardenafil on-demand period with dose-adjustment was performed. International Index of Erectile Function scores after this time period were $24.8 \%, 32 \%$, and $48.2 \%$ for placebo, penile rehabilitation, and on-demand dosing, respectively, and were statistically significant. This trial suggests that on-demand PDE5 inhibitor dosing after prostatectomy may be the optimum treatment schedule.

\section{Intracavernosal injection}

Intracorporeal formulations of alprostadil, papaverine, and phentolamine are injected into the corporal bodies to achieve erections by promoting smooth muscle relaxation. They have a wide variety of applications and can be successful in all forms of erectile dysfunction. Intracorporeal injections were first shown to be effective in 1983 by Brindley et al. ${ }^{41}$ Intracorporeal injections have also been used after radiation therapy and demonstrated very high success rates in a small number of patients. ${ }^{42}$ Despite neurogenic factors relating to erectile dysfunction, intracorporeal injections have been successful as well. ${ }^{43}$ Montorsi et $\mathrm{al}^{44}$ have also shown that the injections can be utilized successfully in the penile rehabilitation setting.

Alprostadil injections 6 months after radical prostatectomy led to erections sufficient for intercourse in $67 \%$ of patients versus $20 \%$ in a control group. ${ }^{44}$ Other studies have cited response rates as high as $90 \%{ }^{44} \mathrm{~A}$ moderately large questionnaire study examined 117 patients with post-prostatectomy erectile dysfunction who had failed a trial of PDE5 inhibitors and were provided with intracorporeal injections. ${ }^{45}$ In sexually active patients, intracorporeal injections were associated with significantly improved erectile function. Furthermore, a review by Mulhall et al showed greater patient satisfaction rates and a greater return of spontaneous functional erections for intracorporeal injections, as compared with PDE5 inhibitors. ${ }^{46}$ Unfortunately, despite the high rate of effectiveness, up to $80 \%$ of patients may withdraw from therapy due to dissatisfaction with response, pain, or other factors. ${ }^{47,48}$ One of the greatest difficulties with penile injections is the negative reaction men have towards the thought of a needle inserted into the penis. A small study showed that the majority of patients experienced little to no pain from the needle or medication, and for men with pain the severity was relatively low. ${ }^{49}$ This is important to note because short-term psychological counseling to educate patients on these factors might improve outcomes and long-term acceptance of injection therapy. ${ }^{50}$

On a similar note, intraurethral use of alprostadil has been effective for the treatment of erectile dysfunction. The effectiveness of intraurethral medications is in the range of $30 \%-55 \%$ to provide an erection sufficient for intercourse. ${ }^{51}$ Unfortunately, the use of intraurethral alprostadil has not been extensively studied in the post-surgical setting of radical prostatectomy. Intracorporeal injections or intraurethral use of vasoactive substances may be a good second-line therapy in men who do not experience good improvement with oral medications such as the PDE5 inhibitors.

\section{Penile prosthesis}

The surgical placement of a penile prosthesis is widely used for erectile dysfunction, regardless of the etiology. It is typically the treatment strategy of choice after other treatment options have failed. Semi-rigid and inflatable devices are available. The inflatable device affords the advantage of a natural experience, given that it can be deactivated and made flaccid when not in use. The main risks are infection and erosion, although infection rates are typically less than $2 \%{ }^{52}$ Satisfaction rate among patients and partners using penile prostheses is the highest of all the various treatment modalities for erectile dysfunction, being as high as $85 \%-90 \% .^{53}$ In broader terms, the three-piece inflatable penile prosthesis has one of the highest patient satisfaction rates for all medically implanted devices and the lowest mechanical revision rates. ${ }^{54}$

A study by Menard et al examined a database of over 400 patients and showed penile prosthesis placement after radical prostatectomy has a complication rate of less than $5 \%$ for infection, revision, or mechanical failure, as well as an overall satisfaction rate of $86.1 \% .{ }^{55}$ Furthermore, in this study, patients with post-radical prostatectomy and a penile prosthesis were compared with patients with vasculogenic erectile dysfunction and a penile prosthesis. ${ }^{55}$ There were no significant differences with respect to surgical complications, 
mechanical failure, or infections. In addition, the overall satisfaction rates ranged from $86 \%$ to $90 \%$ and were similar between the groups. Megas et $\mathrm{al}^{56}$ performed a comparative study of a penile prosthesis and PDE5 inhibitors, with favorable results for the penile prosthesis. The functional and satisfaction scores improved in both groups, but the overall degree of change was greater for the prosthesis group at 12 , 18 , and 24 months following surgery.

\section{Conclusion}

Patients who undergo surgical removal of the prostate, whether by radical prostatectomy or cystoprostatectomy, will often experience impairment of erection in the early postoperative period due to disruption of blood and nerve supply. Surgical technique, nerve-sparing status, patient age, comorbid conditions, and pretreatment potency status all have an effect on post-surgical erectile dysfunction. Vacuum erection devices, oral PDE5 inhibitors, intracorporeal injections, and penile prostheses are used for treatment and rehabilitation. Erectile rehabilitation has been shown to provide more rapid return of erectile function. With careful patient counseling and proper treatment selection, high patient satisfaction and improved erectile function can be achieved. We advise that patients use a vacuum erection device daily in the early postoperative period in combination with either on-demand or daily PDE5 inhibitors. As the erectile function improves, the dependency on one or the other can be withdrawn. For patients who do not respond to a vacuum erection device or PDE5 inhibitors, consideration should be given to intraurethral alprostadil, intracorporeal injections, or a penile prosthesis.

\section{Disclosure}

The authors report no conflicts of interest in this work.

\section{References}

1. National Cancer Institute. SEER Stat Fact Sheets: Prostate Cancer. Surveillance, Epidemiology, and End Results Program. Available from: http://seer.cancer.gov/statfacts/html/prost.html. Accessed November 17, 2013.

2. Heidenreich A, Bellmunt J, Bolla M, et al. EAU guidelines on prostate cancer: screening, diagnosis, and treatment of clinically localised disease. Eur Urol. 2011;59:61-71.

3. Meyer JP, Gillat DA, Lockyer R, MacDonagh R. The effect of erectile dysfunction on quality of life of men after radical prostatectomy. $B J U$ Int. 2003;92:929-931.

4. Mulhall JP, Bella AJ, Briganti A, McCullough A, Brock G. Erectile dysfunction rehabilitation in the radical prostatectomy patient. $J$ Sex Med. 2010;7(4 Suppl 2):1687-1698.

5. Mulhall JP, Mongentalar A. Penile rehabilitation should become the norm for radical prostatectomy patients. J Sex Med. 2007;4:538-543.

6. Briganti A, Gallina A, Suardi N, et al. Predicting erectile function recovery after bilateral nerve sparing radical prostatectomy: a proposal of a novel preoperative risk stratification. $J$ Sex Med. 2010;7:2521-2531.
7. Mulhall JP. Defining and reporting erectile function outcomes after radical prostatectomy: challenges and misconceptions. $J$ Urol. 2009;181:462-471.

8. Potosky AL, Davis WW, Hoffman RM, et al. Five-year outcomes after prostatectomy or radiotherapy for prostate cancer: the Prostate Cancer Outcomes Study. J Natl Cancer Inst. 2004;69:1358-1367.

9. Akbal C, Tinay I, Simsek F, et al. Erectile dysfunction following radiotherapy and brachytherapy for prostate cancer: pathophysiology, prevention, and treatment. Int Urol Nephrol. 2008;40:355-363.

10. Namiki S, Ishidoya S, Tochigi T, et al. Health-related quality of life after intensity modulated radiation therapy for localized prostate cancer: comparison with conventional and conformal radiotherapy. Jpn J Clin Oncol. 2006;23:330-333.

11. Steineck G, Helgesen F, Adolfsson J, et al. Quality of life after radical prostatectomy or watchful waiting. $N$ Engl J Med. 2002;347: 790-796.

12. Herr HW. Quality of life of incontinent men after radical prostatectomy. J Urol. 1994;151:652-654.

13. Schroeck FR, Krupski TL, Sun L, et al. Independent predictors for dissatisfaction with and regret of treatment choice after radical prostatectomy. J Urol. 2008;179 Suppl 4:109.

14. Ratcliff CG, Cohen L, Pettaway CA, Parker PA. Treatment regret and quality of life following radical prostatectomy. Support Care Cancer. 2013;21:3337-3343.

15. Rosen RC, Cappelleri JC, Gendrano N. The International Index of Erectile Function (IIEF): a state-of-the-science review. Int J Impot Res. 2002;14:226-244.

16. Rosen RC, Cappelleri JC, Smith MD, et al. Development and evaluation of an abridged, 5-item version of the International Index of Erectile Function (IIEF-5) as a diagnostic tool for erectile dysfunction. Int $J$ Impot Res. 1999;11:319-326.

17. Mulhall JP, Goldstein I, Bushmakin AG, Cappelleri JC, Hvidsten K. Validation of the erection hardness score. J Sex Med. 2007;4:1626-1634.

18. Porst H, Gilbert C, Collins S, et al. Development and validation of the quality of erection questionnaire. $J$ Sex Med. 2007;4:372-381.

19. Lue TF. Physiology of penile erection and pathophysiology of erectile dysfunction. In: Wein AJ, Kavoussi LR, Novick AC, Partin AW, Peters CA, editors. Campbell-Walsh Urology. Philadelphia, PA, USA: Elsevier Saunders; 2011.

20. Walsh PC, Donker PJ. Impotence following radical prostatectomy: insight into etiology and prevention. J Urol. 1982;128:492-497.

21. Walsh PC. Anatomic radical prostatectomy: evolution of the surgical technique. J Urol. 1998;160:2418-2424.

22. Roumeguere T, Bollens R, Vanden Bossche M, et al. Radical prostatectomy: a prospective comparison of oncological and functional results between open and laparoscopic approaches. World $J$ Urol. 2003;20:360-366.

23. Walsh PC, Marschke P, Ricker D, Burnett AL. Patient reported urinary continence and sexual function, after anatomic radical prostatectomy. J Urol. 2000;55:58-61.

24. Kendirci M, Bejma J, Hellstrom WJ. Update on erectile dysfunction in prostate cancer patients. Curr Opin Urol. 2006;16:186-195.

25. Hatzimouratidis K, Burnett AL, Hatzichristou D, et al. Phosphodiesterase type 5 inhibitors in postprostatectomy erectile dysfunction: a critical analysis of the basic science rationale and clinical application. Eur Urol. 2009;55:334-337.

26. Teloken P, Mesquita G, Montorsi F, Mulhall J. Post-radical prostatectomy pharmacological penile rehabilitation: practice patterns among the International Society for Sexual Medicine Practitioners. J Sex Med. 2009;6:2032-2038.

27. Montorsi F, Guazzoni G, Strambi LF, et al Recovery of spontaneous erectile function after nerve-sparing radical retropubic prostatectomy with and without early intracavernous injections of alprostadil: results of a prospective, randomized trial. J Urol. 1997;158:1408-1410.

28. McCullogh AR. Prevention and management of erectile dysfunction following radical prostatectomy. Urol Clin North Am. 2001;28: 613-627. 
29. Raina R, Agarwal A, Ausmundson S, et al. Early use of vacuum constriction device following radical prostatectomy facilitates early sexual activity and potentially earlier return of erectile function. Int J Impot Res. 2006;18:77-81.

30. Brison D, Seftel A, Sadeghi-Nejad H. The resurgence of the vacuum erection device (VED) for treatment of erectile dysfunction. J Sex Med. 2013;10:1124-1135.

31. Colombo F, Cogni M, Deiana G, et al. [Vacuum therapy]. Arch Ital Urol Nephrol Androl. 1992;64:267-269.

32. Nadig PW, Ware JC, Blumoff R. Noninvasive device to produce and maintain an erection-like state. Urology. 1986;27:126-131.

33. Zippe CD, Raina R, Thukral M, Lakin MM, Klein EA, Agarwal A. Management of erectile dysfunction following radical prostatectomy. Curr Urol Rep. 2001;2:495-503.

34. Gontero P, Fontana F, Zitella A, Montorsi F, Frea B. A prospective evaluation of efficacy and compliance with a multistep treatment approach for erectile dysfunction in patients after non-nerve sparing radical prostatectomy. BJU Int. 2005;95:359-365.

35. Köhler TS, Pedro R, Hendlin K, et al. A pilot study on the early use of the vacuum erection device after radical retropubic prostatectomy. $B J U$ Int. 2007;100:858-862.

36. Schwartz EJ, Wong P, Graydon RJ. Sildenafil preserves intracorporeal smooth muscle after radical retropubic prostatectomy. J Urol. 2004;171 771-774

37. Raina R, Lakin MM, Agarwal A, et al. Long term effect of sildenafil citrate following radical prostatectomy: 3-year follow-up. Urology. 2003;62:110-115.

38. Montorsi F, Nathan HP, McCullough A, et al. Tadalafil in the treatment of erectile dysfunction following bilateral nerve sparing radical retropubic prostatectomy: a randomized, double-blind, placebo controlled trial. $J$ Urol. 2004;172:1036-1041.

39. Nehra A, Grantmyre J, Nadel A, et al. Vardenafil improved patient satisfaction with erectile hardness, orgasmic function and sexual experience in men with erectile dysfunction following nerve sparing radical prostatectomy. J Urol. 2005;173:2067-2071.

40. Montorsi F, Brock G, Lee J, et al. Effect of nightly versus on-demand vardenafil on recovery of erectile function in men following bilateral nerve-sparing radical prostatectomy. Eur Urol. 2008;54:924-931.

41. Brindley GS. Cavernosal alpha-blockade: a new technique for investigating and treating erectile impotence. Br J Psychiatry. 1983;143: 332-337.

42. Pierce LJ, Whittington R, Hanno PM, et al. Pharmacologic erection with intracavernosal injection for men with sexual dysfunction following irradiation: a preliminary report. Int J Radiat Oncol Biol Phys. 1991;21:1311-1314.

43. Chao R, Clowers DE. Experience with intracavernosal tri-mixture for the management of neurogenic erectile dysfunction. Arch Phys Med Rehabil. 1994;75:276-278.
44. Montorsi F, Guazzoni G, Strambi LF, et al. Recovery of spontaneous erectile function after nerve sparing radical retropubic prostatectomy with and without early intracavernous injections of alprostadil: results of a prospective randomized trial. J Urol. 1997;158:1408-1410.

45. Domes T, Chung E, DeYoung L, MacLean N, Al-Shaiji T, Brock G. Clinical outcomes of intracavernosal injection in postprostatectomy patients: a single-center experience. Urology. 2012;79:150-155.

46. Mulhall JP, Simmons J. Assessment of comparative treatment satisfaction with sildenafil citrate and penile injection therapy in patients responding to both. BJU Int. 2007;100:1313-1316.

47. Purvis K, Egdetveit I, Christiansen E. Intracavernosal therapy for erectile failure - impact of treatment and reasons for drop-out and dissatisfaction. Int J Impot Res. 1999;11:287-299.

48. Lehmann K, Casella R, Blochlinger A, et al. Reasons for discontinuing intracavernous injection therapy with prostaglandin E1 (alprostadil). Urology. 1999;55:397-400.

49. Albaugh J, Ferrans CE. Patient-reported pain with initial intracavernosal injection. J Sex Med. 2009;6:513-519.

50. Lottman PE, Hendriks JC, Vruggink PA, et al. The impact of marital satisfaction and psychological counselling on the outcome of ICItreatment in men with ED. Int J Impot Res. 1998;10:83-87.

51. Raina R, Agarwal A, Ausmundson S, Mansour D, Zippe CD. Long-term efficacy and compliance of MUSE for erectile dysfunction following radical prostatectomy: SHIM (IIEF-5) analysis. Int J Impot Res. 2005; 17:86-90.

52. Montague DK, Angermeier KW. Current status of penile prosthesis implantation. Curr Urol Rep. 2000;1:291-296.

53. Kabalin JN, Kuo JC. Long-term followup of and patient satisfaction with the Dynaflex self-contained inflatable penile prosthesis. J Urol. 1997; 158:456-459.

54. Wilson SK, Delk JR, Salem EA, Cleves MA. Long-term survival of inflatable penile prostheses: single surgical group experience with 2384 first-time implants spanning two decades. J Sex Med. 2007;4: 1074-1079.

55. Menard J, Tremeaux JC, Faix A, Pierrevelcin J, Staerman F. Erectile function and sexual satisfaction before and after penile prosthesis implantation in radical prostatectomy patients: a comparison with patients with vasculogenic erectile dysfunction. J Sex Med. 2011;8: 3479-3486.

56. Megas G, Papadopoulos G, Stathouros G, Moschonas D, Gkialas I, Ntoumas K. Comparison of efficacy and satisfaction profile, between penile prosthesis implantation and oral PDE5 inhibitor tadalafil therapy, in men with nerve-sparing radical prostatectomy erectile dysfunction. BJU Int. 2012;112:169-176.
Research and Reports in Urology

\section{Publish your work in this journal}

Research and Reports in Urology is an international, peer-reviewed, open access journal publishing original research, reports, editorials, reviews and commentaries on all aspects of adult and pediatric urology in the clinic and laboratory including the following topics: Pathology, pathophysiology of urological disease; Investigation and treatment of

\section{Dovepress}

urological disease; Pharmacology of drugs used for the treatment of urological disease. The manuscript management system is completely online and includes a very quick and fair peer-review system, which is all easy to use. Visit http://www.dovepress.com/testimonials.php to read real quotes from published authors. 